Original Research Paper

\title{
Using Linear Chouquet Integral Algorithm to Design Optimal Time-Cost Model in Large Construction Projects
}

\author{
${ }^{1}$ Hamid Jafari Nia, ${ }^{2}$ Kaveh Ostad-Ali-Askari and ${ }^{1}$ Hamidreza Babaali \\ ${ }^{I}$ Department of Civil Engineering, Khorramabad Branch, Islamic Azad University, Khorramabad, Iran \\ ${ }^{2}$ Department of Water Engineering, College of Agriculture, Isfahan University of Technology (IUT), Isfahan, Iran
}

\section{Article history}

Received: 09-08-2020

Revised: 31-10-2020

Accepted: 18-11-2020

Corresponding Author:

Kaveh Ostad-Ali-Askari Department of Water Engineering, College of Agriculture, Isfahan University of Technology (IUT), Isfahan 84156 83111, Iran

Emails: ostadaliaskari.k@of.iut.ac.ir kaveh.oaa2000@gmail.com

\begin{abstract}
Nowadays, the problem of scheduling and executing projects with the least cost and time has become one of the main concerns of project managers. In this regard, researchers have used different methods and patterns. One of these methods is to use concurrent engineering in projects. Simultaneous engineering means the creation of a project schedule for projects based on existing units and human resources so that a synchronous rule can be applied to the project so that the project can be completed in less time. Modeling time and cost in large-scale construction projects is actually complicated and complicated. These complexities actually increase the risk of time and cost in the project. In this research, a new method called Chouquet integral algorithm is used to analyze time and cost equations. The Chouquet integral is a method used to analyze and linearize complex equations. The proposed method is implemented on an executable model in 2017 and analyzed and analyzed in MATLAB software. The results show that the error rate of time and cost in the construction model resulted in a reduction of 27 and $14 \%$, respectively. Commonly, the structure developments will take an extended period to broad. In this background approximating structure costs are main stages for plan estimators, independents. The evaluating procedure is a stimulating occupation owing to variations in building features and that trend rising over the extended period. The movement time-cost association has for the most portion been presumed to be lined, but, a rare revisions have recommended that this is not essentially the situation in exercise. These prototypes carefully represent the most public circumstances happening throughout construction developments. The benefits of these models are that they tolerate for together separate and constant, in addition to deterministic outlines. Moreover, the amount of possessions needed for deafening the movement can be measured. Contrasts amongst the models and additional new fast-following model from the procedure are debated and a Chouquet integral algorithm is applied for a fictional usage instance including together density methods.
\end{abstract}

Keywords: Construction Management, Chouquet Integral, Linear Analysis, Error

\section{Introduction}

Given the evolving trend of different industries and the rise of new development plans and consequently the rise of various industrial and business projects, the innovationdriven economy, the development of skills and knowledge and the motivation of the workforce and the ability to intelligently respond to change An economy-driven environment must have the proper planning and management based on a systematic approach to the planning, control and execution of projects in terms of time and cost (Gransberg et al., 2017). Project management is the process by which the project should achieve the most appropriate and cost-effective way during its lifetime (Huntsman et al., 2017). In other words, project planning and control is a process, in order to maintain the project's path to achieving a justified economic balance between the three factors of cost, time and quality during project implementation, which requires specific tools and techniques to achieve these goals. To be 
used. On the other hand, when departing from the program path, it is possible to return the project to its closest possible original path ( 2 and 3 ) by identifying the causes (Huntsman et al., 2017; Ilbeigi et al., 2014).

Project planning and control can be effective when it comes to facilitating implementation when systematically implemented. In addition to overseeing the physical and financial progress of the project, project control can be managed by the manager in areas where problems such as excessive administrative costs, lack of resources and materials, failure to execute key project activities in due date, etc., can be addressed. Help the project identify the solution and control the adverse consequences of the problem (Ilbeigi et al., 2017; Chalabi et al., 1980). In many cases, the problem can be rescheduled and rescheduled.

One of the issues related to implementing largescale projects, especially in the field of construction, is to be able to execute several projects that form a subplan of a single large-scale project at the same time. The problem with concurrent execution is that projects can be timed to match. Failure to comply with the project concurrently causes financial losses and in fact leads to many problems. Therefore, a method needs to be developed that can produce reliable results for large projects (Jeong et al., 2017; Bowman, 1994).

To assess the impact of concurrency on Engineering, Procurement and Construction (EPC) implementation, we first need to identify the workflow and information in these projects. A project is performed in four stages: Product definition, design, preparation and sample testing, as well as reliability and quality testing (Joseph Shrestha et al., 2016). Figure 1 shows the network structure of a project. This is an overview of the workflow and information in the project and the communication displayed in this structure reflects the interactions that exist between the various stages of the project. Some of these interactions are (Chalabi et al., 1980; Jeong et al., 2017):

1). Advancements in the job or information stage can be limited by the slow progress of the job and information stages. These streams are displayed in a line

2). Tasks obtained by a single step in the provisioning process may require rework. Using the work requires a change in the receiving stage and the work done in this step also needs to be changed and reworked

$3)$. Re-work requires the coordination between the rediagnostic stage and the re-creation phase. This coordination must be done before resuming work

In the model, each of these stages has a general structure, with elements similar to these structures being distinguished at different stages by phase indices. Activities performed may be incorrect or based on information or inaccuracies and may therefore require a radical change.
We call the workaround to correct errors or respond to changes in the information on which the activity was based.

The physical and information linkage between the activities of the various stages of the project as well as the existence of these relationships between the activities of a single stage limit the processes at that stage. These constraints are often expressed in terms of the length of time that an activity is performed. They are therefore called prerequisite relationships. Management decisions, coordination mechanisms, the type of information that is exchanged between different stages of the project and the amount, skill and experience of the staff involved, as well as the number of manpower in the project, can also influence project progress (Ballesteros-Perez et al., 2019; Bettemir and Birgönül, 2017).

\section{The Relation Works}

Many studies have been carried out on the old project cost-relationship relationships in the Earned Value Management (EVM) method and other studies that have used the parameters of the method in constructing a model and a new forecasting relationship as well as many research studies (Lin, 2008). In the context of project cost estimation, construction projects have been investigated using non-EVM methods. Based on studies of the use of forecasting methods to estimate project time and cost, it is concluded that the present value management approach is also an effective and effective way of predicting completion time and cost (Liu, 2003; Meyer and Shaffer, 1965). The project is considered and research on the use of this method in cost estimation is ongoing. Also, by reviewing the research done, it has been concluded that the models and methods presented so far have some features such as complexity, need for programming to build them, dependency on project type, dependency on Countries' currency or time dependence, inability to make predictions at any given time in the project and inaccurate estimates (Arashpour et al., 2017; 2016).

It has done extensive research on project cost estimation using the resulting value management approach and has obtained results by examining the results of other researchers (Joukar and Nahmens, 2016). Some of the results are: (1) Research shows that it is not possible to say that a relationship is best in all situations, (2) accuracy of performance indicator models is a function of system, stage and phase of the project, Cost, Consumer Price Index (CPI) is more important than Schedule Performance Index (SPI), 4In the early stages of the project, relationships based on the Scheduled Cost Index (SCI) and in the final stages of the project, relationships. Based on CPI, they are better predictors. 5. Among the weighted predictor relationships, the relationships in which the SPI index is 0.2 weighted have the best performance (Ahn and Erenguc, 1998; Deckro and Hebert, 1989). 


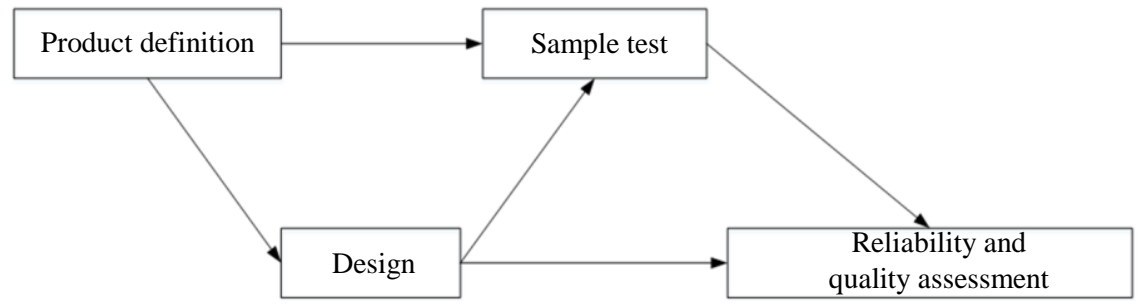

Fig. 1: Network structure of a design project

It was also investigated the accuracy of cost-predictive relationships during a study. He concludes that the CPI index is a good factor in predicting the cost of completing a project (Li et al., 2018; Diaby et al., 2011).

It was used a fast turbulence genetic algorithm and a support vector machine to construct a model called the Evolved Support vector Machine (ESIM) model. This model is able to estimate the cost of completing construction projects with greater accuracy than EVM relationships (Khalaf et al., 2010; Moon et al., 2018). The authors used 10 parameters affecting the cost of construction projects that 5 parameters out of 10 parameters are the main parameters and performance indicators of EVM relationships as input variables of the model (Liberatore and Pollack-Johnson, 2006). This paper uses information from two reinforced concrete construction projects to train and test the model, respectively (Lin, 2011). Information from all 13 projects was also used to compare the 8 relationships of the predictive relationships of the EVM method with the proposed model. The comparison results show that the prediction error of the ESIM model is less than the prediction error of the EVM relationships (Lin et al., 2015; Ahmed and Arocho, 2020).

It was done in addition to genetic algorithms with fast perturbation and support vector machine. Have used fuzzy logic in constructing another model called Evolutionary Model of Fuzzy Backup Vector Machine (EFSIM) to predict the cost of completing construction projects. The results of comparing the EFSIM model with the ESIM model and the eight relationships of the predictive relationships of the EVM method show that the prediction error of the EFSIM model is the least and this model is able to estimate the cost with very little error (Moon et al., 2018; Cusack, 1985).

It was proposed a new approach by integrating a progressive model and acquired scheduling method Employment Services (ES) to improve the predictive accuracy of the cost-predictive relationships of completion of construction projects in the value-added method (Vrat and Kriengkrairut, 1986; Wakas and Leong, 2009). Have. In this study, the first four progressive models of Logistic, Gompertz, Bass and Weibull are compared in estimating the cost of 9 construction projects. Comparative results show the superiority of the Gompertz model in cost estimation (Shane et al., 2009; Deckro et al., 1995).
It was examined four methods based on artificial intelligence (artificial neural network, high-order neural network, fuzzy logic and genetic algorithm) in the development of a model called fuzzy neural network for estimation (Kelley Jr, 1961). The costs of construction projects have been used. In this study, 10 qualitative and quantitative variables affecting the cost of construction projects are considered as input variables of the model (Yang, 2007). The model output variable is the final cost of the project. Model results show that the model error in cost estimation is on average $10 \%$ which indicates high accuracy of model (Shahandashti, 2014; Ehsani et al., 2017).

It was proposed two models to predict the cost of asphalt resurfacing projects using artificial neural networks (Khosrowshahi, 1997; Li et al., 2018). In this study, a model is constructed for each of the two contract pricing methods (unit price method and cut price method) (Lin et al., 2015; Sunde and Lichtenberg, 1995). For the construction and testing of two models of unit cost and cross-section pricing methods, data from 103 and 68 asphalt resurfacing projects were used, respectively. The results show that the prediction accuracy of the two models of unit cost and cross-sectional price methods are in good and medium order, respectively (Shahandashti and Ashuri, 2016; Arashpour et al., 2015a-b).

\section{Materials and Methods}

In studies using multiple criteria decision-making methods, the scores obtained for each option are examined according to the effect of each criterion, but the interaction between the criteria is not considered. Criteria affect each other and the sum of these effects must be examined (Nonobe and Ibaraki, 2006). Therefore, the model used to aggregate the criterion effect should be able to consider these relationships. Since linear models do not have this capability, the choke integral is used for integration (Peng and $\mathrm{Yu}, 2008$; Perera, 1980). Choke integrals are one of the best aggregation methods that can be used if the criteria are dependent. Validation is computed using Chouquet integrals taking into account the interaction between criteria. The use of the Chouquet integral method has been considered for a robust model in which the metrics work together and has been used in various cases (Joseph Shrestha et al., 2016; Elghaish et al., 2019). 
In this method, the weighted vector of the weighted sum method is replaced by a uniform set function called capacity $(\mu)$. The Chouquet integral with respect to the capacitance $(\mu)$ on the $X$ vector is defined as follows (Shahandashti and Ashuri, 2016):

$$
\begin{aligned}
& C \mu(x)=\Sigma x(i)\left[\mu(A(i)) n_{i}=1-\mu(A(i+1))\right] \\
& =\Sigma \mu(A(i))\left[x(i) n_{i}=1-x(i-1)\right]
\end{aligned}
$$

$\mu(S)$ indicates the importance or weight of the set $S$ of the criteria.

Given that the importance of each subset of criteria is not necessarily equal to the sum of its members, the interaction of criteria is taken into account in the calculation of the final score. Given the above relation, for each subset $S$ of factors must be determined $\mu(S)$, so it increases exponentially with increasing number of elements (Fulkerson, 1961; Shane et al., 2009).

In the multi-criteria decision-making discussions, the above interaction is ignored and limited to the interactions between the two criteria. Therefore, the simplified case of the quadratic integral is called the integral quadratic integral. In this case, the integral formula of the Chouquet will be as follows (El-Sayegh and El Haj, 2015; Erenguc, 2001; Huntsman et al., 2017; Ilbeigi et al., 2014; 2017):

$$
x=\sum v_{i} x_{i}-\sum\{i, j\} \subseteq N, \frac{I_{i j}}{2}\left|x_{i}-x_{j}\right|
$$

In the above relation, $x_{i}$ indicates the advantage that an option has been obtained in factor $i . v_{i}$ is the significance factor of each factor and $I_{i j}$ is the interaction factor of two factors. The model coefficients (coefficients of significance and coefficients of interaction of criteria) must be determined for the use of the Chouquet integral. In large-scale problems where there are complex relationships between criteria, the decision maker cannot directly determine the coefficients, in which case learning methods are used to determine the coefficients. The decision maker is then asked to make a paired comparisons that he or she is certain of the number of alternatives he/she is considering; the reference or selected $A \subseteq A^{\wedge}$ 'alternatives. This preference information is used as learning data to discover the intellectual form of decision making (Pujitha and Venkatesh, 2020). After determining the coefficients that are consistent with the decision maker's preference information, they can be used to score and rank other options (Querns, 1989). This way the decision maker does not have to determine the coefficients in advance. Because of their high flexibility, these models can be very effective in determining choke integral coefficients (Hariga et al., 2019; Shahandashti, 2014).
The mathematical relation of the continuous Chouquet integral between the two variables is obtained as follows:

$\int_{c} h o g=C_{g}(n)=\sum_{i=1}^{n} h\left(x_{\pi_{i}}\right)\left[g\left(A_{i}\right)-g\left(A_{i-1}\right)\right]$

In this equation $h\left(x_{\pi_{i}}\right)$ is the query supporting the $h$ th information source. Also $g\left(A_{i}\right)$ is the value of combining resources to the $i$ th source and $g\left(A_{i-1}\right)$ is the value of combining $(i-1)$ th resources. The expression $\left[g\left(A_{i}\right)-g\left(A_{i-1}\right)\right]$ also indicates the value that $\pi_{i}$ is the trusted source of information in answering questions.

In the Chouquet integral method, mathematical operators are used to increase the effectiveness of the method. One of these mathematical operators is Einstein's operation. Einstein's operations are effective cumulative operators based on algebraic software, which include Einstein's multiplication of $\otimes_{E}$ and Einstein's sum of $\otimes_{E}$. For each $(a, b) \in[0,1]^{2}$ we will have the following equations (Cusack, 1985):

$$
\begin{aligned}
& a \otimes_{E} b=\frac{a b}{1+(1-a)(1-b)} \\
& a \oplus_{E} b=\frac{a+b}{1+a b}
\end{aligned}
$$

Suppose $\Omega$ is a set of triangular intuitive numbers $\tilde{a}_{j}=<\left(\underline{a}_{j}, a_{j}, \bar{a}_{j} ; u_{a_{i}}, v_{a_{i}}>,(j=1,2, \ldots, n)\right.$. The Triangular Intuitive Fuzzy Einstein (TIFEWG) dimension $\mathrm{n}$ is as follows (Goh and Hall, 2013; Gransberg et al., 2017):

$$
\text { TIFEWG }: \Omega^{n} \rightarrow \Omega
$$

So:

$\operatorname{TIFEWG}\left(\tilde{a}_{1}, \tilde{a}_{2}, \ldots, \tilde{a}_{n}\right)=\left(\oplus_{j=1}^{n}\right)_{E} a_{j}^{\omega}$

In the above relation $\omega=\left(\omega_{1}, \omega_{2}, \ldots, \omega_{n}\right)^{T}$ is the weighted vector $a_{j}$ and $\sum_{j=1}^{n} \omega_{j}=1$.

$$
\text { If } \tilde{a}_{j}=<\left(\underline{a}_{j}, a_{j}, \bar{a}_{j} ; u_{a_{i}}, v_{a_{i}}>,(j=1,2, \ldots, n)\right. \text { is a set of }
$$
triangular intuitive numbers, then the sum of the values is subtracted The TIFEWG operator is also a triangular intuition and is obtained by the following relation:

$$
\begin{aligned}
& \operatorname{TIFEWG}\left(\tilde{a}_{1}, \tilde{a}_{2}, \ldots, \tilde{a}_{n}\right)=\left(\oplus_{j=1}^{n}\right)_{E} a_{j}^{\omega}=<\left(\prod_{j=1}^{n} \underline{a}_{j}^{\omega_{i}}, \prod_{j=1}^{n} a_{j}^{\omega_{i}}, \prod_{j=1}^{n} \bar{a}_{j}^{\omega_{i}}\right) \\
& =\left(\frac{2 \prod_{j=1}^{n} u_{a_{i}}^{\omega_{i}}}{\prod_{j=1}^{n}\left(2-u_{\bar{a}_{i}}\right)^{\omega_{i}}+\prod_{j=1}^{n} u_{\bar{a}_{i}}^{\omega_{i}}}, \frac{\prod_{j=1}^{n}\left(1+v_{a_{i}}^{\omega_{i}}\right)-\prod_{j=1}^{n}\left(1-v_{a_{i}}^{\omega_{i}}\right)}{\prod_{j=1}^{n}\left(1+v_{a_{i}}^{\omega_{i}}\right)+\prod_{j=1}^{n}\left(1-v_{a_{i}}^{\omega_{i}}\right)}\right)
\end{aligned}
$$


where, $\omega=\left(\omega_{1}, \omega_{2}, \ldots, \omega_{n}\right)^{T}$ is the weighted vector $\sum_{j=1}^{n} \omega_{j}=1$.

If $f$ is a positive real function on $X=\left\{x_{1}, x_{2}, \ldots, x_{n}\right\}$ and $\mu$ is a fuzzy measure on $X$, then the discrete Chouquet integral $f$ with respect to $\mu$ is defined as the following relation:

$$
C_{\mu}(f)=\sum_{i=1}^{n} f_{(i)}\left[\mu\left(A_{(i)}\right)-\mu\left(A_{(i+1)}\right)\right]
$$

where, $A_{(i)}=\left\{x_{(i)}, \ldots, x_{(n)}\right\}$ and $A_{(n+a)}=\varnothing$ such that $f_{(1)} \leq$ $f_{(2)} \leq \cdots f_{(n)}$.

\section{Proposed Method}

The basis of the new forecasting method is based on the use of the Chouquet integral method to solve the problem of time and cost management in large-scale construction projects. As explained, this method follows the linear equations of the nonlinear model prediction of time and cost. In the previous section, the theory of the Chouquet integral method was expressed. In this section, we present a linear prediction model by Chouquet integral.

In nonlinear models of time and cost prediction, the obvious factor is the maximization of the forecast error, the complexity of the time and cost model. The cost objective function is defined as follows:

$$
\sum_{t=1}^{T} \rho_{t} L_{t} \log \left(\frac{C(t)}{L(t)}\right)
$$

The cost model includes equations for describing technology, subtractive and diffusion characteristics. Impurities. The output cost is as follows:

$$
Q_{t}=a_{t} L_{t}^{1-\gamma} k_{t}^{\gamma}
$$

where, $Q_{t}$ is the output cost impurity, $a_{t}$ the degree of overall factor of production, $k_{t}^{\gamma}$ cost savings over period $t$ and $\gamma$ the amount of savings. The subtraction attribute is defined as follows (Joseph Shrestha et al., 2016; Joukar and Nahmens, 2016):

$$
A_{t}=b_{1} Y_{t}^{b_{2}}
$$

where, $A_{t}$ is the degree of cost reduction in period $t$ and $Y_{t}^{b_{2}}$ time control in period $t$.

On the other hand we have:

$$
Y_{t}=1-\frac{E_{t}}{\sigma_{t} Q_{t}}
$$

where, $E_{t}$ is the time error rate in the period of $t$ and $\sigma_{t}$ of the recovery factor. The net performance based on the cost of implementation is as follows (Cho, 2003):

$\Gamma_{t}=Q_{t}-A_{t} Q_{t}-D_{t} Y_{t}$

We use the Chouquet integral to solve the time and cost prediction problem. If we define $X$ as the vector of the cost variable that is $x_{i j}, \Omega$ represents part of the prediction model for the constraints expressed that is satisfying in period $t$. We define the expected function cost function $w_{t}$ as follows:

$$
\begin{aligned}
& w_{t}=\sum_{i} E\left\{c_{i t} g_{i t}\right\} \\
& \min \sum_{t} \sum_{i} c_{i t}\left(1-x_{i t}\right)+\sum_{t} \min \left\{w_{t} \mid(\text { costraints })\right\}
\end{aligned}
$$

The prediction constraints are as follows:

$$
\begin{aligned}
& x_{i t}=1 \text { for } t \leq e_{i} \text { or } t \geq l_{i}+d_{i} \\
& x_{i t}=0 \text { for } e_{i} \leq t \leq s_{i}+d_{i} \\
& x_{i t}=0 \text { or } 1 \text { for } e_{i} \leq t \leq l_{i}
\end{aligned}
$$

These include distribution constraints, seasonal constraints, available resources and optimal scheduling. If $t$ is below the problem of a linear program, it can be replaced by the binary given in the Chouquet. Douglas Lagrange's problem for the following $t$ is as follows:

$$
L_{t}=\max _{k, \pi, y, \zeta, \mu}\left\{L_{t}(k, \pi, y, \zeta, \mu)\right\}
$$

where, $L_{t}(k, \pi, y, \zeta, \mu)$ is a Lagrangian function and $(k, \pi, y$, $\zeta, \mu)$ are the constraint coefficients:

$$
\begin{aligned}
& L_{t}(k, \pi, y, \zeta, \mu)=\min _{g \geq 0}\left\{\mathrm{w}_{t}\right. \\
& +\sum_{i} k\left(\left(\sum_{k} s_{i k} f_{k t}\right)+g_{i t}+r_{i t}-d_{i t}\right)+\sum_{i} \pi_{i t}\left(g_{i t}-\bar{g}_{i t} x\right) \\
& \left.+\sum_{i} y_{i t}\left(r_{i t}-d_{i t}\right)+\sum_{k} g\left(\left|f_{k t}\right|-\bar{f}_{k}\right)+\bar{\mu}_{t}\left(\left(\sum_{i} r_{i t}\right)-\varepsilon\right)\right\}
\end{aligned}
$$

The $T$ subdomain is then replaced by $L_{t}$ :

$$
\min \sum_{t} \sum_{i} C_{i t}\left(1-x_{i t}\right)+L_{t}
$$

The following $T$ th problem is possible if and only if the following optimal values for the problem are less than 2 :

$$
\begin{aligned}
& \min E\left\{\sum_{i} r_{i t}\right\} \\
& \text { S.T.Sf }+g+r=d \quad g \leq g(\varphi) X \quad r \leq d \\
& |f| \leq \bar{f}(\varphi)
\end{aligned}
$$


Dugan Lagrange is as follows:

$$
\max _{\vartheta, \lambda, \tau, \eta} U_{t}(\vartheta, \lambda, \tau, \eta)
$$

where, $U_{t}(\vartheta, \lambda, \tau, \eta)$ are the Lagrangian function and $\vartheta, \lambda$, $\tau$, are the constraint coefficients:

$$
\begin{aligned}
& U_{t}(\vartheta, \lambda, \tau, \eta) \\
& =\min _{g \geq 0}\left\{\sum_{i} r_{i t}+\sum_{i} v_{i t}\left(\left(\sum_{i} \sum_{t} s_{i t} f_{i t}\right)+g_{i t}+r_{i t}-d_{i t}\right)\right. \\
& \left.+\sum_{i} \lambda_{i t}\left(g_{i t}-\bar{g}_{i} x_{i t}\right)+\sum_{i} \tau_{i t}\left(r_{i t}-d_{i t}\right)+\sum_{k} \tau_{k t}\left(\left|f_{k t}\right|-\bar{f}_{k}\right)\right\}
\end{aligned}
$$

We then go into the general problem of analyzing the Chouquet:

$$
\begin{aligned}
& \text { Min } z \\
& \text { S.T. } z \geq \sum_{t} \sum_{i} C_{i t}\left(1-x_{i t}\right) \\
& +\sum_{t} L_{t}(k, \pi, y, \zeta, \mu) \text { for } k, \pi, y, \zeta, \mu \geq 0 \\
& \sum_{t} v_{t}(\vartheta, \lambda, \tau, \eta) \leq \epsilon \text { for } \vartheta, \lambda, \tau, \eta \geq 0
\end{aligned}
$$

The main problem is a numerical programming problem that is solved using trial and error method for predictive decision variables. This is part of the main issue that only includes some of the restrictions. Once $x_{i t}$ is fixed, it makes the sub-problem independent of the other sub-problems. In each iteration, solving the dual coefficients produced by the sub-problem, the cost and the ability to determine the cost vary. These double multipliers are repeated in the form of one or more of the constraints added to the problem below. Finally the linear prediction problem must follow the following optimal pattern:

$$
\min z \geq \sum_{t} \sum_{i}\left\{c_{i t} \tilde{g}_{i}\left(1-x_{i t}\right)\right\}
$$

If the following are probable issues, the cost for the period $t, w_{t}$, depends on the use of units to satisfy the constraints of each time period, with the aim of maintaining high capability. $\varepsilon(\varphi)$ is the degree of capability. Therefore, the cost in period $t$ can be expressed as follows:

$$
\begin{aligned}
& w_{t}=\min E\left\{\sum_{t} c_{i t} g_{i t} x_{i t}^{n}\right\} \\
& \text { S.T.Sf }+g+r=d(\varphi) \\
& g \leq \bar{g}(\varphi) x^{n} r \leq d(\varphi)|f| \leq \bar{f}(\varphi) \\
& \sum_{i} r_{i t} \leq \varepsilon(\varphi)
\end{aligned}
$$

Solving subsystems is not complicated, since project data is available during the $t$ period and allows us to minimize performance costs. The final cost rate is as follows:

$$
z \geq \sum_{t}\left(w_{t}^{n}+\sum_{i}\left(c_{i t} \tilde{g}_{i}\left(1-x_{i t}^{n}\right)+\pi_{i t}^{n} \tilde{g}_{i}\left(x_{i t}^{n}-x_{i t}\right)\right)\right)
$$

where, $w_{t}^{n}$ is the expected output for period $t$ for $\mathrm{nth}$ solution. The coefficient below the problem may not have any solution due to the fact that the output produced cannot be exceeded desirable. If a sub-issue is impossible, the cut is impossible. For each impossible sub-problem the result of the nth problem-solving method, the following is impossible to cut:

$$
E\left\{\sum_{i} r_{i t}^{n}\right\}+\sum_{i} \lambda_{i t}^{n} \tilde{g}_{i}\left(x_{i t}^{n}-x_{i t}\right) \leq \varepsilon
$$

The coefficient $\lambda_{i t}^{n}$ is interpreted as the boundary decrease in the output produced.

\section{Numerical Results}

As illustrated in this study, the Chuquet integral method is used to manage time and cost in large-scale construction projects. In the previous section, the proposed method and the mathematical theory of this method are presented. In this section, the numerical results of this method are evaluated. MATLAB software was used to evaluate and present numerical results on a construction model.

\section{Data Collection}

This paper uses information from 21 actual projects completed with a total duration of 719 months to build and test the time and cost forecasting model of construction projects. It should be noted that all projects have been implemented in Iran. The model building uses information from 17 projects with a total duration of 541 months and the model data from 4 projects with a total time of 178 months. Projects are very diverse in terms of type. As a result of a variety of civil engineering projects including two complementary dams, road projects such as freeway and road construction, construction projects, water and wastewater projects such as construction of pipelines, canals and tunnels. Construction of a new city irrigation and drainage and sewage system, preparation and landscaping projects of a new city and projects of industrial structures such as silos have been used in the evaluation. 
Hamid Jafari Nia et al. / American Journal of Engineering and Applied Sciences 2020, 13 (4): 707.716 DOI: 10.3844/ajeassp.2020.707.716

Table 1: Estimating time and cost in the proposed model

\begin{tabular}{|c|c|c|c|c|c|c|c|c|c|c|c|}
\hline Project/variable & 1 & 2 & 3 & 4 & 5 & 6 & 7 & 8 & 9 & 10 & 11 \\
\hline Output variable & 1.44400 & 1.72200 & 1.09400 & 1.36400 & 1.78200 & 1.16700 & 1.6770 & 1.73900 & 1.21500 & 1.11900 & 1.06400 \\
\hline Real time & 30.00000 & 18.00000 & 13.00000 & 60.00000 & 40.00000 & 23.00000 & 52.00000 & 41.00000 & 8.00000 & 26.00000 & 16.00000 \\
\hline Error & 0.00289 & 0.01005 & 0.00119 & 0.00600 & 0.00507 & 0.00411 & 0.00521 & 0.00576 & 0.06710 & 0.00125 & 0.00084 \\
\hline Cost reduction & 19.10000 & 12.18000 & 16.30000 & 15.41000 & 13.54000 & 16.63000 & 15.27000 & 18.34000 & 15.72000 & 14.45000 & 13.90000 \\
\hline Project/variable & 12.00000 & 13.00000 & 14.00000 & 15.00000 & 16.00000 & 17 & Test 1 & Test 2 & Test 3 & Test 4 & \\
\hline Output variable & 1.00000 & 1.22200 & 1.04700 & 1.08200 & 1.08200 & 2.104 & 1.49400 & 1.25000 & 1.67800 & 1.15900 & \\
\hline Real time & 54.00000 & 20.00000 & 14.00000 & 20.00000 & 20.00000 & 86 & 31.00000 & 9.00000 & 96.00000 & 42.00000 & \\
\hline Error & 0.00130 & 0.01037 & 0.04080 & 0.00484 & 0.00103 & 0.011 & 0.00978 & 0.00557 & 0.02400 & 0.01167 & \\
\hline Error reduction & 15.13000 & 9.25000 & 12.45000 & 9.33000 & 11.47000 & 10.55 & 16.48000 & 14.20000 & 17.96000 & 10.14000 & \\
\hline Cost reduction & 11.33000 & 14.49000 & 15.40000 & 12.53000 & 16.92000 & 15.43 & 13.61000 & 11.35000 & 13.67000 & 15.84000 & \\
\hline
\end{tabular}

Table 2: Model error estimation

\begin{tabular}{llrrrr}
\hline Project/variable & 9 & 11 & 13 & \multicolumn{1}{r}{14} & 15 \\
\hline Output variable & 1.2150 & 1.06400 & 1.00000 & 1.2220 & 1.04700 \\
Real time & 8.0000 & 16.00000 & 20.00000 & 14.0000 & 20.00000 \\
Error & 0.0671 & 0.00361 & 0.01037 & 0.0408 & 0.00484 \\
\hline
\end{tabular}

Compare the Results of the Model with the Results of the EVM Relationships

The model error value and the optimal relationship error value of the EVM method in predicting the cost of completing each project of the 21 projects used in model building and testing are shown in Table 1. It should be noted that opt. Is the one that has the least error. The value of the second optimal relationship error for the projects that have the best performance of the EVM method relative to the model is shown in Table 2 (Zhu et al., 2007). It can be seen in Table 1 that the Chouquet integral model estimates and reduces the cost of completing 16 of the 21 projects most accurately to the optimal relationship of the EVM method. Table 2 also shows that the proposed model estimates the cost of completing the other 5 projects more accurately than the second optimal relationship. Therefore, it can be said that the proposed model has a better overall performance in reducing project costs. Outdated plan distribution organizations have established incompetent in enlightening general routine. In reaction to this, Combined Plan Distribution has been planned and applied in plans through the construction manufacturing. Combined Plan Distribution prepares an innovative predetermined, developmental and structural situation for distributing construction plans, over improving combined and cooperative preformation. It is an advanced plan transfer technique, considered by initial, cooperative and cooperative appointment through all stages of bringing a plan. Earned value management is a measureable plan organization method for calculating plan development and to prepare plan contributors with initial cautions where the plan is organization 'over the cost' or 'after the schedule'. It was prepared indication of Grossed assessment organization being positively used on numerous actual plans to distribute precise price metrics. "Assessment method is a vital method in examining and governing the presentation of a plan". Earned value management, as mention by Plan Organization Association, is a real instrument for providing cost and plan displays, to quantity routine through Budget Presentation Proportion and Program Routine Proportion standards:

$C P R=\frac{A C W P}{B C W P}$

$S P R=\frac{B C W S}{B C W P}$

Wherever $A C W P$ denotes the real budget of effort achieved, $B C W P$ denotes the planned price of effort accomplished and $B C W S$ denotes the planned budget of effort planned. The accomplishment standards are defined in accord with the subsequent components; (1) CPI $<1$ shows that the cost presentation is underprivileged, $\mathrm{CPI}=1$ shows that the cost presentation is well-organized and CPI $>1$ designates that the cost routine is brilliant. Applying Earned value management, accomplishments can be dignified as alteration not routine, for example Cost Alteration (CV) and Schedule Variance (SV). CA $<0$ designates a plan over economical, a $\mathrm{CA}=0$ shows a plan on economical and a $\mathrm{CA}>0$ shows a plan under economical:

$$
\begin{aligned}
& C A=B C W P-A C W P \\
& S V=B C E P-B C W S
\end{aligned}
$$

\section{Conclusion}

This paper presents an optimal way to manage time and cost and reduce it in large construction projects. The proposed method is based on the application of the Chouquet integral. This method was used to break down 
time and cost equations into linear and simple equations. The proposed method has shown that the use of the Chouquet integral can significantly reduce the time and cost model error when faced with a large and complex model. It also enables parallel analysis for simultaneous projects. The method used can also be used to predict time and cost models in large construction projects. Condensing an agenda with the purpose of restriction a structure development's period is occasionally essential for gathering goals or modifying suspensions. But, as will be realized earlier, most revisions have combined agenda density Chouquet integral algorithms that take for decided definite pre-recognized associations amongst commotion periods and their costs. The greatest public of these prospects has remained the time-cost occupation-off association to be line. This earnings while a movement is compacted its cost rises linearly per unit of period compacted. Other suppositions combined in density Chouquet integral algorithms modeling have comprised: Presumptuous restrictions by how much the accomplishments can be stopped and abandoning the efficacy cost experienced as more possessions effort concurrently on the similar commotion. In specific, the last explanation has been beginning important nonconformities amongst strategic and real periods in actual structure plans, as lately examined in place structure. Many of these generalizations were formerly prepared so as to decrease the computational determination needed to get optimum compacted programs. But, donating rigid experiential indication was prepared densely and considerable advanced. The different contains of a model that denotes considerable more accurately the movement period and cost association. Henceforth, the planned model suggests a novel, more precise different for assessing the subcomponents of the independent purpose in preparation density difficulties. The relationship model strategic can support plans conditional on whether or not possessions effort collaboratively. It similarly includes accurate inconstant and components that are typically recognized, or can be rationally approached, while performing construction developments. Lastly, it similarly permits for design of the quantity of possessions needed for attaining diverse stages of density. Approaching optimization Chouquet integral algorithm that instrument the models planned here will thus be more demonstrative. It will be organized as monitors: The Nonfiction analysis will prepare an indication of the greatest applicable zones. The approaches division will define the model planned with its different variations. It will be applied to compute the costs related with each of the belongings and the consequences will be contrasted with a lately advanced fast model from the procedure. The model will be used to a pretended plan in the commotion deafening and fast models will be engaged together concurrently and distinctly.

\section{Acknowledgement}

This research was supported by the Isfahan University of Technology. We thank our all authors who provided insight and expertise that greatly assisted the research.

\section{Funding Information}

This paper is part of several studies of a group of Researchers, Professors and students of Civil Engineering from Iran. The research group does not receive any funding to support it.

\section{Author's Contributions}

All authors contributed to design the study, write and revise the manuscript.

\section{Ethics}

The present Study and ethical aspect were approved by the Isfahan University of Technology. The present study was approved by the Isfahan University of Technology.

\section{References}

Ahmed, S., \& Arocho, I. (2020). Analysis of cost comparison and effects of change orders during construction: Study of a mass timber and a concrete building project. Journal of Building Engineering, 101856.

Ahn, T., \& Erenguc, S. S. (1998). The resource constrained project scheduling problem with multiple crashable modes: a heuristic procedure. European Journal of Operational Research, 107(2), 250-259.

Arashpour, M., Bai, Y., Aranda-mena, G., BabHadiashar, A., Hosseini, R., \& Kalutara, P. (2017). Optimizing decisions in advanced manufacturing of prefabricated products: Theorizing supply chain configurations in off-site construction. Automation in Construction, 84, 146-153.

Arashpour, M., Wakefield, R., Abbasi, B., Lee, E. W. M., \& Minas, J. (2016). Off-site construction optimization: Sequencing multiple job classes with time constraints. Automation in construction, 71, 262-270.

Arashpour, M., Wakefield, R., Blismas, N., \& Minas, J. (2015a). Optimization of process integration and multi-skilled resource utilization in off-site construction. Automation in Construction, 50, 72-80.

Arashpour, M., Wakefield, R., Blismas, N., \& Maqsood, T. (2015b). Autonomous production tracking for augmenting output in off-site construction. Automation in construction, 53, 13-21. 
Ballesteros-Perez, P., Elamrousy, K. M., \& GonzálezCruz, M. C. (2019). Non-linear time-cost trade-off models of activity crashing: Application to construction scheduling and project compression with fast-tracking. Automation in Construction, 97, 229-240.

Bettemir, Ö. H., \& Birgönül, M. T. (2017). Network analysis algorithm for the solution of discrete timecost trade-off problem. KSCE Journal of Civil Engineering, 21(4), 1047-1058.

Bowman, R. A. (1994). Stochastic gradient-based timecost tradeoffs in PERT networks using simulation. Annals of Operations Research, 53(1), 533-551.

Chalabi, A. F., Lai, R., \& Staehr, T. W. (1980). An Interactive Construction Control System for Project Planning and Estimating. In Computing in Civil Engineering (pp. 140-150). ASCE.

Cho, S. B. (2003). Sequential estimation and crashing in PERT networks with statistical dependence. International journal of industrial engineering-theory applications and practice, 10(4), 391-399.

Cusack, M. M. (1985). A simplified approach to the planning and control of cost and project duration. Construction Management and Economics, 3(3), 183-198.

Deckro, R. F., \& Hebert, J. E. (1989). Resource constrained project crashing. Omega, 17(1), 69-79.

Deckro, R. F., Hebert, J. E., Verdini, W. A., Grimsrud, P. H., \& Venkateshwar, S. (1995). Nonlinear time/cost tradeoff models in project management. Computers \& Industrial Engineering, 28(2), 219-229.

Diaby, M., Cruz, J. M., \& Nsakanda, A. L. (2011). Project crashing in the presence of general nonlinear activity time reduction costs. International Journal of Operational Research, 12(3), 318-332.

Ehsani, E., Kazemi, N., Olugu, E. U., Grosse, E. H., \& Schwindl, K. (2017). Applying fuzzy multiobjective linear programming to a project management decision with nonlinear fuzzy membership functions. Neural Computing and Applications, 28(8), 2193-2206.

Elghaish, F., Abrishami, S., Hosseini, M. R., AbuSamra, S., \& Gaterell, M. (2019). Integrated project delivery with BIM: An automated EVM-based approach. Automation in Construction, 106, 102907.

El-Sayegh, S. M., \& El Haj, R. (2015). Time-cost-float optimization in construction projects. In Civil-Comp Proceedings (Vol. 108). Civil-Comp Press.

Erenguc, S. S., Ahn, T., \& Conway, D. G. (2001). The resource constrained project scheduling problem with multiple crashable modes: An exact solution method. Naval Research Logistics (NRL), 48(2), 107-127.

Fulkerson, D. R. (1961). A network flow computation for project cost curves. Management science, 7(2), 167-178.
Goh, J., \& Hall, N. G. (2013). Total cost control in project management via satisficing. Management Science, 59(6), 1354-1372.

Gransberg, D. D., Jeong, H. D., Karaca, I., \& Gardner, B. (2017). Top-down construction cost estimating model using an artificial neural network.

Hariga, M., Shamayleh, A., \& El-Wehedi, F. (2019). Integrated time-cost tradeoff and resources leveling problems with allowed activity splitting. International Transactions in Operational Research, 26(1), 80-99.

Huntsman, B., Glover, B., Huseynov, S., Wang, T., \& Kuzio, J. (2017). Highway cost index estimator tool (No. PRC 17-73). Texas A\&M Transportation Institute.

Ilbeigi, M., Ashuri, B., \& Hui, Y. (2014). A stochastic process to model the fluctuations of asphalt cement price. In Construction Research Congress 2014: Construction in a Global Network (pp. 1111-1118).

Ilbeigi, M., Ashuri, B., \& Joukar, A. (2017). Timeseries analysis for forecasting asphalt-cement price. Journal of Management in Engineering, 33(1), 04016030.

Jeong, D. H., Gransberg, D., \& Shrestha, K. J. (2017). Advanced Methodology to Determine Highway Construction Cost Index (HCCI) (No. FHWA/MT-17-006/8232-001). Montana Department of Transportation.

Joseph Shrestha, K., Jeong, H. D., \& Gransberg, D. D. (2016). Current practices of highway construction cost index calculation and utilization. In Construction Research Congress 2016 (pp. 351-360).

Joukar, A., \& Nahmens, I. (2016). Volatility forecast of construction cost index using general autoregressive conditional heteroskedastic method. Journal of construction engineering and management, 142(1), 04015051.

Kelley Jr, J. E. (1961). Critical-path planning and scheduling: Mathematical basis. Operations research, 9(3), 296-320.

Khalaf, W. S., June, L. W., Abu Bakar, M. R. B., \& Soon, L. L. (2010). A linear programming approach to maximize savings by stretching noncritical activities. Australian Journal of Basic and Applied Sciences, 4(11), 5649-5657.

Khosrowshahi, F. (1997). The optimum project duration and cost curve for Hong Kong public housing projects. Engineering Construction and Architectural Management, 4(4), 249-269.

Li, W., Hu, J., Zhang, Z., \& Zhang, Y. (2018). A Novel Traffic Flow Data Imputation Method for Traffic State Identification and Prediction Based on SpatioTemporal Transportation Big Data. In CICTP 2017: Transportation Reform and Change-Equity, Inclusiveness, Sharing and Innovation (pp. 79-88). Reston, VA: American Society of Civil Engineers. 
Liberatore, M. J., \& Pollack-Johnson, B. (2006). Extending project time-cost analysis by removing precedence relationships and task streaming. International Journal of Project Management, 24(6), 529-535.

Lin, D., Xu, X., \& Pu, F. (2015). Bayesian information criterion based feature filtering for the fusion of multiple features in high-spatial-resolution satellite scene classification. Journal of Sensors, 2015.

Lin, E. Y. (2011). An alternate solution approach towards the time-cost tradeoff problem on activity-on-arc project network. International Journal of Operations and Quantitative Management, 17, 49-57.

Lin, F. T. (2008). Time-cost tradeoff problem based on confidence-interval estimates and level $(1-\alpha)$ fuzzy numbers, International Journal of Innovative Computing, Information and Control. 4, 2551-2564.

Liu, S. T. (2003). Fuzzy activity times in critical path and project crashing problems. Cybernetics \&Systems, 34(2), 161-172.

Meyer, W. L., \& Shaffer, L. R. (1965). Extending CPM for multiform project time-cost curves. Journal of the Construction Division, 91(1), 45-67.

Moon, S., Chi, S., \& Kim, D. Y. (2018). Predicting construction cost index using the autoregressive fractionally integrated moving average model. Journal of Management in Engineering, 34(2), 04017063.

Nonobe, K., \& Ibaraki, T. (2006). A metaheuristic approach to the resource constrained project scheduling with variable activity durations and convex cost functions. In Perspectives in Modern Project Scheduling (pp. 225-248). Springer, Boston, MA.

Peng, W., \& Yu, H. (2008, July). DTCTP with renewable and nonrenewable resources. In 2008 Chinese Control and Decision Conference (pp. 170-175). IEEE.

Perera, S. (1980). Linear programming solution to network compression. Journal of the Construction Division, 106(3), 315-326.
Pujitha, K. S. V. S., \& Venkatesh, K. (2020). Forecasting the construction cost by using unit based estimation model. Materials Today: Proceedings.

Querns, W. R. (1989). Project expediting. AACE International Transactions, D-3.

Shahandashti, M. (2014). Analysis of the temporal relationships between highway construction cost and indicators representing macroeconomic and construction and energy market conditions. In Construction Research Congress 2014: Construction in a Global Network (pp. 1103-1110).

Shahandashti, S. M., \& Ashuri, B. (2016). Highway construction cost forecasting using vector error correction models. Journal of management in engineering, 32(2), 04015040.

Shane, J. S., Molenaar, K. R., Anderson, S., \& Schexnayder, C. (2009). Construction project cost escalation factors. Journal of Management in Engineering, 25(4), 221-229.

Sunde, L., \& Lichtenberg, S. (1995). Net-present-value cost/time tradeoff. International Journal of Project Management, 13(1), 45-49.

Vrat, P., \& Kriengkrairut, C. (1986). A goal programming model for project crashing with piecewise linear time-cost trade-off. Engineering costs and production economics, 10(2), 161-172.

Wakas, S. K., \& Leong, W. (2009). Cost reduction for the project completion in shortest possible duration by stretching noncritical activities. Australian Journal of Basic and Applied Sciences, 3(4), 4526-4533.

Yang, I. T. (2007). Performing complex project crashing analysis with aid of particle swarm optimization algorithm. International Journal of Project Management, 25(6), 637-646.

Zhu, G., Bard, J. F., \& Yu, G. (2007). A two-stage stochastic programming approach for project planning with uncertain activity durations. Journal of Scheduling, 10(3), 167-180. 